\section{Performance social versus arte: \\ hibridações poéticas ${ }^{1}$}

Social performance versus art: poetics hybridization

Elder Sereni Ildefonso ${ }^{2}$

Gabriela Pereira Fregoneis ${ }^{3}$

\section{RESUMO}

Este artigo tem como intuito discutir e refletir sobre questões inerentes as problemáticas da performance social, mais especificamente as derivações e zonas de fronteira com a arte. É fator importante, nas argumentações, um olhar para a América Latina, tão produtiva neste campo de ação e ainda com pouca visibilidade em nosso território. Na composição teórica serão utilizados os conceitos "chaveamento" de Erving Goffman e a "liminaridade" de Victor Turner.

Palavras-chave: Performance. Intervenções artísticas. Arte e sociedade.

\section{ABSTRACT}

This paper has as purpose to discuss and reflect on issues involved in the problems of social performance, more specifically the derivations and border areas with art. It is a important factor in the arguments a look at Latin America, as productive in this area of action and with little visibility in our territory. In the theoretical composition will be used the concepts "keying" of Erving Goffman and "Timinal" of Victor Turner.

Keywords: Performance. Artistic interventions. Art and society.
1.

O artigo foi desenvolvido a partir de trabalho apresentado no evento III Colóquio Internacional de Estudos Linguísticos e Literários em 2014 na Universidade Estadual de Maringá.

2.

Professor Temporário na Universidade Estadual de Maringá. Mestre em Artes pela Universidade Estadual Paulista Júlio de Mesquita Filho (UNESP).

Contato:

eisereni@gmail.com ORCID: http://orcid.org/ 0000-0001-6667-3871

3.

Professora Temporária na Universidade Estadual de Maringá. Doutoranda em Artes da Cena pela Universidade Estadual de Campinas.

Contato:

gabiangelus@hotmail.com ORCID: http://orcid.org/

0000-0003-0877-6092

Submetido em: 30/og/2016, aceito em: 09/12/2016. 
Não é recente este campo de estudo associando a arte, já que muitos têm sido os estudos sobre o entrelaçamento entre arte/vida e arte/sociedade. O maior objetivo que tange a escrita desse artigo diz respeito à análise de algumas performances de cunho político realizadas na América Latina e seus possíveis embasamentos em torno das performances sociais. Dentre as inúmeras performances realizadas recentemente, escolhemos duas que mais nos chamaram a atenção por seu caráter singular e seu viés político social: a performance Mugre (1999), do performer colombiano Rosemberg Sandoval, e Proyecto Filoctetes (2002), do grupo El Periférico de Objectos, dirigido por Emilio García Wehbi. Para dar conta de tão vasto campo de investigação, utilizaremos dois conceitos para auxiliar no delineamento da pesquisa: o conceito de "chaveamento" do sociólogo canadense Erving Goffman e o de "liminaridade", de Victor Turner. O professor e pesquisador americano Marvin Carlson diz que:

[...] se perguntarmos o que faz das artes performáticas serem performáticas, eu imagino que a resposta sugerirá, de algum modo, que elas requerem a presença física de seres humanos treinados ou especializados, cuja demonstração de certa habilidade seja a performance (GOFFMAN, apud CARLSON, 2009, p. 13).

Carlson toma como base um dos princípios básicos da performance, o estado de "presença". Colocar-se presente, por meio da arte performática, vai além da relação entre corpo/tempo/ espaço. A presença aqui é tomada como um ato político e de compartilhamento entre os indivíduos. Rosemberg Sandoval, em sua performance Mugre, trabalha sobre este viés, ou seja, o performer colombiano desloca a "presença física" do mendigo" do seu território liminar para um território "divino" tais como os museus e salas de exposições. Profana esse novo espaço (termo usado por Agamben em sua obra Profanações), gerando um deslocamento entre objeto e lugar. Já a obra Filoctetes traz outra ideia de presença, na medida em que a figura humana vivificada por meio de bonecos hiper-realistas - desloca situações urbanas tendendo a desterritorializar a percepção dos transeuntes observadores. Há então uma inversão perceptiva, já que o boneco é encarado como uma possível representação humana chamando a atenção para os olhares das pessoas que transitam nesses espaços e que passeiam pela dinâmica do cotidiano para uma presença de espectador. A ausência de vida dos bonecos potencializa a presença dos observadores, colocando-os como "protagonistas" da cena do real. Esta fronteira entre o corpo e a representação do corpo, presença e ausência, justapõe-se à estranheza das situações em que estes se encontram.
4.

Optamos pela definição "mendigo", palavra que carrega preconceitos históricos, para reforçar a ideia de invisibilidade deste indivíduo perante a sociedade, nesta obra em específico a visibilidade somente acontece a partir de sua objetificação e utilização como material de trabalho do artista. No entanto, é notável que há especificidades para definir cada pessoa em situação de rua, portanto, de modo algum estamos generalizando e descaracterizando as individualidades e peculiaridades. 
As experiências performativas em Mugre e El Proyecto Filoctetes, interessam a esta pesquisa sob a perspectiva da existência em um espaço-tempo compartilhado por meio da arte, ressaltando suas efemeridades e que optam por uma associação ao que Dewey (2010) diz: "uma iniciação e uma consumação"? Não há em si uma definição que restrinja o início e fim da experiência; ela evolui de acordo com as eventualidades que a concernem e assim se distribuem na relação espaço/tempo, viabilizando a insurgência poética de tal arte que cria uma fricção com o simulacro social, desvelando outras possibilidades relacionais a partir da ação artística.

Para refletir sobre a obra de Sandoval e os processos e procedimentos artísticos que nos conduzem às zonas liminares, recorreremos às inflexões de Victor Turner para desenvolver paralelos entre uma arte de resistência e questionadora da esfera social, criando deslocamentos referenciais da esfera pública e viabilizando terreno fértil para discussões entre a performance e sociedade. O antropólogo escocês Victor Turner inspirou-se no conceito de liminaridade de Arnold Van Gennep, antropólogo alemão, sobre os ritos de passagem, sendo que estes dividem-se em: separação, margem e agregação. A margem é caracterizada com certa autonomia dos outros dois momentos, devido ao que Gennep desenrola como liminar, que caracteriza o ideal próprio de passagem do rito em questão. Para este entendimento sobre a complexidade da limininaridade, é importante a compreensão de que alguns de seus instantes de existência se revelam potencialmente estranhos e familiares; assim, põem em prova a própria sistematização da vida em um fluxo normativo, de modo a tornar complexas justamente as eventualidades transitórias de um sujeito ou grupo perante a vida.

O conceito de liminaridade desenvolvido por Turner dentro do campo da Antropologia da Performance ${ }^{5}$ consegue friccionar a ordem natural dos eventos estabelecidos na sociedade buscando uma transformação social por meio das performances e ritos. Se contextualizarmos suas formulações, verifica-se que ele está ligado às interpretações sobre os ritos de passagem, ou seja, momentos de transição e contraste social. O sujeito liminar é um indivíduo "transitante", em busca de transformação. Como nos diz o próprio Turner:

[...] as entidades liminares não se situam aqui nem lá; estão no meio e entre as posições atribuídas e ordenadas pela lei, pelos costumes e convenções [...] Assim a liminaridade frequentemente é comparada à morte, ao estar no útero, à invisibilidade, à escuridão, à bissexualidade, as regiões selvagens e ao eclipse do sol ou da lua (TURNER, 1974, p. 117).

Por esta guia, nossa pesquisa se afeiçoa com o que é marginal, por ser este o lugar da borda em que se discute a instabi-
5.

O conceito foi desenvolvido por Turner em seus estudos sobre a sociedade Ndembu no noroeste da Zâmbia, África Central. 
lidade dos sistemas ou um contínuo transitar que cria fricções na tessitura social. As performances citadas situam-se intencionalmente em ambiente liminar, em que "um ambiente simbólico representa ao mesmo tempo uma sepultura e um útero" (TURNER, 1974, p. 118).

Falamos em um não-lugar ao referirmos às pesquisas artísticas que estabelecem diálogo nesta zona liminar de discussão da esfera pública. Assim, destina-se a criar interfaces com a performance social. Para que esta reflexão ocorra com proximidades aos pensamentos sobre liminaridade, faz-se necessário uma mudança de perspectiva em uma transgressão na recepção do mundo a partir de um olhar performativo, no deslocamento semântico que equivale ao poético/reflexivo no fazer artístico.

Estar deslocado ou transgredir o simulacro social é criar oportunidades de observar as forças que subjazem ao indivíduo em situações liminares. A experiência se potencializa na presença quando articula realidades por meio do discurso artístico efêmero. Nesta reflexão, o pensamento sobre a formação do indivíduo ocorre não em uma estrutura, mas na fricção entre estruturas, prevendo constantes trânsitos de entendimento e ação sobre a vida individual e social. A reflexão sobre esta busca por zonas liminares é fortuita para o artista, visto que quanto mais ele estiver deslocado em relação à norma e conseguir compreender as zonas de intersecção entre sistemas vigentes, será mais viável a rearticulação de seu lugar de ação na esfera pública.

A obra, Mugre, consiste em levar um mendigo para dentro da galeria de arte e esfregá-lo na parede e no chão e finaliza-se ao devolvê-lo à rua. Mugre transborda este contorno teórico que nos impele a pesquisa, sendo que um estado liminar é evocado na sugestão do olhar performativo do público. Deslocar-se com alguém nas costas não é algo que passe despercebido aos olhares mais atentos no ambiente público, no entanto algo se potencializa no momento em que este alguém é caracterizado como um "esquecido" pela conjuntura social. Sendo assim, Sandoval retoma a discussão sobre os "desaparecidos" urbanos, os que não são vistos mas que sempre estiveram lá, como uma mancha na reputação da presunção capitalista. Pessoas que não são identificáveis pelos quesitos impelidos ao cidadão, pois não funcionam em favor da produtividade.

Neste ponto os mendigos são percebidos como um câncer ${ }^{6}$ estrutural, pois ocupam o espaço e vivem as cidades com maior potência comparado aos que ali transitam, visto que existe uma relação vital com a urbe. Câncer também no sentido de uma proliferação interna aos sistemas e que resiste nos interstícios ou zonas de fricção entre sistemas. Nos mendigos está contida a desestruturação endêmica da estrutura social no tocante à
6.

Aqui entendido como um ente com todas as características dos demais entes similares e que ocupam urbe, mas que em diferenciação aos demais que auxiliam na manutenção do sistema, assim como as células do corpo humano, estes têm uma inserção diversa da produtiva, criando uma potencial instabilidade na organização social produtivista. 
sobrevivência sem a convocatória contínua do "dever contas" ao tempo organizacional capitalista.

Sandoval, ao carregar essa potência (mendigo) que - por um imaginário coletivo social é um ser não funcional -, na arte subjaz um ser que detém em sua pele e roupagem as marcas da falência do capital; toda a sujeira em seu corpo são impregnâncias das problemáticas do constructo intelectual e da práxis da edificação urbana. Nesta pele que contém o descaso está a arte de Mugre. Esfregar o corpo, em geral, é uma ação de limpeza corporal, a qual todos os dias é feita pelos cidadãos "de bem". No caso de Mugre, esta ação não se localiza na ideia de retirar a sujeira do corpo, mas em imprimir esta sujeira na parede e chão brancos, imaculados pela tinta mesma que cobriu toda a falha estrutural reflexiva do projeto arquitetônico moderno, que precisa de constantes reformas por ter a necessidade de sempre estar intocável.

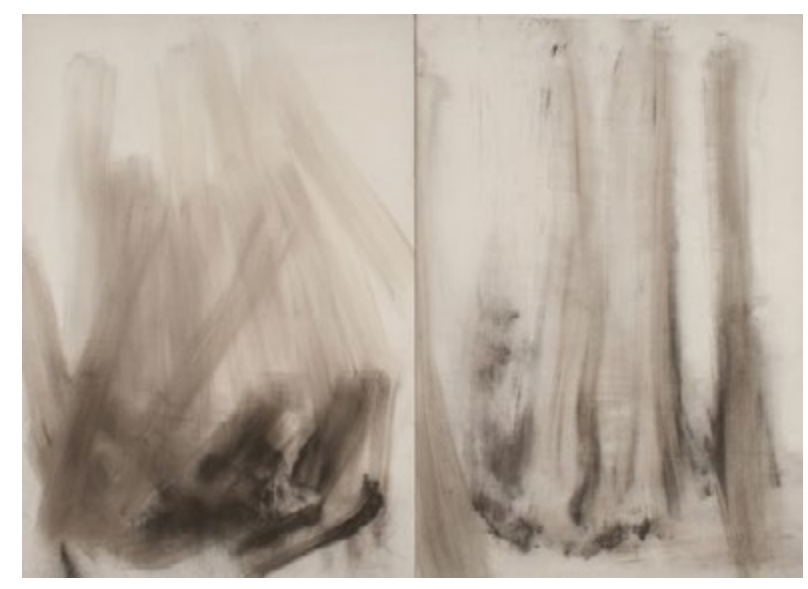

Figura 1. Mugre. Rosemberg Sandoval. Bogotá, Colombia. 1999 Fonte: http://www. casasriegner.com/ exhibition/excavando-/ attachment/rsandobalpinturasucia1999-2003/

No tocante às artes visuais, o cubo branco historicamente é alvo de constantes questionamentos, principalmente a partir da segunda metade do século XX na Europa, quando alguns dos debates se apresentavam na reflexão deste lugar sem identidade poder receber as qualidades alheias, ou seja, da obra em si, e deste modo viabiliza-se o controle sobre os ruídos neste espaço, sem características e que separa arte e vida.

Sandoval retoma essa discussão justapondo cidade, galeria e artista, em que o terceiro se adequa à discussão referida justamente por usar roupa branca, o que potencializa a discrepância entre o artista e o mendigo, já que há apenas esse diferencial entre artista, espaço e material de trabalho (mendigo); essa diferenciação toma sua exponencial amplitude. $O$ ato de esfregar o mendigo nas paredes do espaço é uma ação simples, mas que em Mugre é ressignificada, "esfrega em nossa cara" a condição social atual e a necessidade de que se multipliquem as abordagens artísticas de imediato cunho político, revisando o olhar sobre o fazer artístico por meio da conexão liminar com a 
sociedade. A liminaridade, neste caso em específico, encontrase no fazer artístico, também na criação de diálogo com o mendigo e na concretização da obra de arte que deixa o olhar em suspensão daqueles que presenciam a performance.

Em paralelo à obra Mugre, de Sandoval, engajamos na discussão o trabalho El Proyecto Filoctetes, do grupo El Periférico de Objectos, dirigido por Emilio García Wehbi. O projeto se trata de uma intervenção urbana utilizando 25 bonecos de látex de formas e tamanhos reais humanos e localizados em lugares estratégicos da via pública em Buenos Aires. Os bonecos eram colocados em posições de abandono e acidente. Cada boneco era acompanhado de um grupo de pessoas que registravam as reações dos espectadores que transitavam por essas vias públicas, fazendo suscitar uma reflexão acerca da relação existente entre os indivíduos e as circunstâncias em que eles se encontravam. Segundo Wehbi, o trabalho partiu de três pontos bases:

a) Sua experiência com os objetos, como um dos fundadores do grupo El Periférico de Objectos; b) A dolorosa crise social, política e econômica que havia eclodido em dezembro de 2001 na Argentina e que encheu as ruas da cidade com pessoas sem teto; c) Seu interesse é indagar e sacudir as relações entre espectador e espetáculo. Podemos ver, por meio dos registros fotográficos apresentados no site do grupo, que as reações dos transeuntes eram bem diversas. Uns fingiam que não viam a situação de crise apresentada, outros se disponibilizavam a ajudar diretamente, tocando os objetos e alguns, por não se sentirem à vontade em enfrentar a realidade apresentada sozinhos, denunciavam o acontecido chamando policiais (super-homens sociais) para resolverem o problema. Afim de instigar ainda mais as relações entre a obra e os espectadores, Wehbi utilizou de recursos cênicos hiper-realistas como vômitos e sangue nos bonecos. Por meio de uma experiência estética, Filoctetes busca associar a experiência política/social do sujeito com as situações liminares vividas e apresentadas na vida cotidiana dos argentinos (HEMISPHERIC INSTITUTE, 2016).

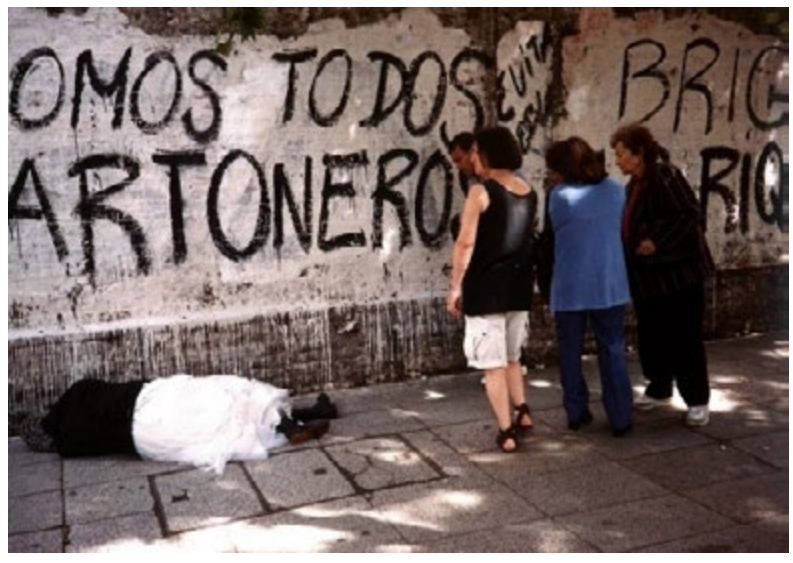

FIGURA 2. $E l$

Proyecto Filoctetes. Emilio Garcia Wehbi. Buenos Aires, Argentina, 2002. Fonte:http://emiliogarciawehbi.com.ar/ performativa/ int_urbana/2002 proyecto_filoctetes_ buenos_aires/es.php
7 .

Acesso pelo site: http:// hemisphericinstitute.org/ journal/4.2/eng/en42_pg_ persino.html. Tradução dos autores. Texto original: a) su experiencia con objetos, como uno de los fundadores del grupo $\mathrm{El}$ Periférico de Objetos, b) la dolorosa crisis social, política y económica que había eclosionado en diciembre del 2001 en Argentina y que sembraba las calles de la ciudad de personas sin techo, c) su interés en indagar y sacudir las relaciones entre espectador y espectáculo. 
No livro "A representacão do eu na vida cotidiana", Goffman apresenta a ideia de "definição da situação", ou seja, a pessoa se pergunta: o que está acontecendo aqui? A partir deste questionamento o indivíduo toma sua decisão e consequente reação frente à situação, buscando sempre uma ação adequada à situação apresentada. A obra Filoctetes trabalha diretamente com essa noção de Goffman, visto que o intuito central do artista é causar um choque entre a intervenção urbana realizada por meio dos bonecos e o registro das possíveis reações dos indivíduos que transitavam nesse espaço urbano. Sob o olhar da performance social para a performance transformativa, Goffman explana sobre a noção de "chaveamento", que se enquadra nas discussões aqui apresentadas. Segundo o sociólogo, os acontecimentos sociais apresentam "faixas de experiências" e que para análise, deve-se realizar o isolamento dessas sequências e assim compreender melhor seu conjunto de ocorrências. Para tanto, Carlson diz que:

[...] o chaveamento está muito mais diretamente conectado com o que normalmente se entende por performance e envolve uma faixa de atividade tão significativa sobre alguns termos que é transformado pela recontextualização em algo com um sentido diferente. Entre as "chaves" básicas da sociedade, Goffman menciona os refazeres lúdicos, como o "faz de conta" (CARLSON, 2009, p.63).

É possível associar a concepção de Emilio Wehbi e a obra Filoctetes sob o viés apresentado por Goffman, no que diz respeito à recontextualização de um acontecimento real por meio de uma prática lúdica, neste caso os bonecos de látex, tendo como foco a tessitura dentro de uma performance transformativa. O perceber. O deslocar. O agir e reagir. O impactar-se com o deslocamento liminar e seu contato com o Mundo. Goffman define performance como

\footnotetext{
"toda atividade de um indivíduo, que ocorre durante um período marcado por sua presença contínua perante um conjunto particular de observadores, e que tem alguma influência sobre esses observadores" (GOFFMAN, apud CARLSON, 2009, p.49).
}

É importante lembrar que Goffman fala em observadores e não em espectadores, pois ao observar e perceber o comportamento do performer este compartilha do momento e da experiência proporcionada pela obra artística, tirando-o da zona passiva do assistir ou simplesmente ver a obra. 


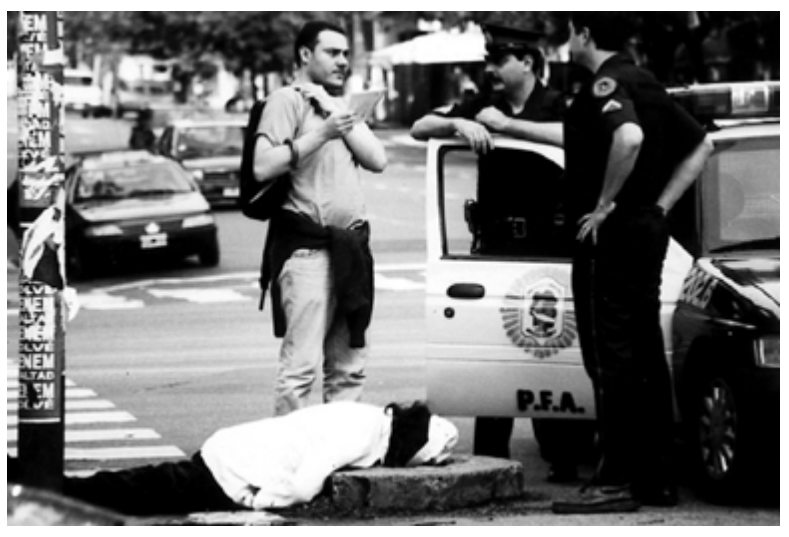

FIGURA 3.

El Proyecto Filoctetes. Emilio Garcia Wehbi. Buenos Aires, Argentina, 2002. Fonte: http:// hemisphericinstitute. org/journal/4.2/ eng/images/42_lg_ persino_04.jpg

Escolhemos trabalhar com Goffman porque ele considera o comportamento social como performance. O sociólogo canadense define uma visão de performance que estabelece sua raiz mais ao contexto social em que o indivíduo/receptor está envolvido do que as atividades específicas da performance. Foi por esse viés que dedicamos a escolha das duas performances para análise, pois ambas debruçam-se sobre problematizações do contexto social mais do que o ato performático em si. O relevante nessas performances é perceber as possíveis relações que se estabelecem entre os sujeitos sociais e a obra performática. Goffman enfatiza que todo comportamento social tem uma audiência, e causa um "efeito" sobre a mesma, ao mesmo tempo em que visa a uma transformação em si. Desta maneira, busca-se destacar as relações entre os papéis sociais e a interação humana.

Para dar continuidade na reflexão acerca das obras Mugre e Filoctetes, recorremos a Dawsey, estudioso de Turner que descreve os cinco momentos da experiência vivida:

1) algo acontece ao nível da percepção (sendo que a dor ou o prazer podem ser sentidos de forma mais intensa do que comportamentos repetitivos ou de rotina); 2) imagens de experiências do passado são evocadas e delineadas - de forma aguda; 3) emoções associadas aos eventos do passado são revividas; 4) o passado articula-se ao presente numa "relação musical" (conforme a analogia de Dilthey), tornando possível a descoberta e construção de significado; e 5) a experiência se completa através de uma forma de "expressão" (DAWSEY, 2006, p. 19).

Tanto a performance de Sandoval como a de Wehbi buscam o caráter de "experiência" com a obra, de vivência por meio de percepções, sensações, emoções, etc. Desta maneira, ambos os artistas utilizam direta ou indiretamente os cinco momentos citados por Dawsey, relacionando a arte com os acontecimentos sociais. A performance defende o olhar da presença como resistência. 
A duas ações criam em território público uma possibilidade de discussão sobre as paisagens urbanas, gerando em si a descontinuidade do cotidiano por meio do deslocamento de referencial das pessoas que presenciam a situação, descontinuidade que viabiliza a reflexão sobre a ocupação do espaço social.

Em Filoctetes, o fato de os bonecos hiper-realistas estarem abandonados nas ruas gera uma modificação no cenário da cidade, já que são semelhantes aos corpos dos ocupantes urbanos em situação de abandono, mas que, em diferença, seu posicionamento está estrategicamente colocado na urbe. Atrai olhares por múltiplas razões, cada um com seu motivador e, para além dele, a conglomeração de pessoas faz gerar uma situação relacional que tende a se multiplicar, para que assim se realize uma averiguação dos fatos sobre a dúvida de ser um humano visivelmente debilitado ou posteriormente, já percebido não ser, quais seriam as intenções de quem colocou os bonecos no espaço.

Segundo Lúcia Maciel de Oliveira, "a multidão é a forma permanente da existência social e política do coletivo" (OLIVEIRA, 2007, p. 71). Esta reflexão nos leva ao pensamento de que neste momento o sujeito assume um corpus coletivo mediado pela percepção em meio aos diálogos propostos pelos que ali se encontram. Nesta concepção, Filoctetes propõe uma democracia perceptiva de sua arte, pois as ponderações sobre a eventualidade são feitas pelo coletivo que se encaminha para uma decisão sobre o andamento da situação. Filoctetes interrompe o que antes era um espaço de livre trânsito e que, após a ação com os bonecos, se torna um lugar de diálogos e diferentes percepções da eventualidade.

Faz-se necessário colocar que por meio das diversas experiências que já tivemos enquanto performers em espaço urbano por meio da performance art, foi perceptível que os transeuntes demostram interesse pulsante pela investigação do que ali acontece, sendo esta peculiaridade de extrema potência, visto que no momento não preexiste a definição de que se trata de uma obra artística por estar na interface entre arte e vida. A relação com a proposição toma um status complexo para compreensão, estimulando a subjetividade.

Este estado de suspensão em que se encontra esta fricção entre arte e vida urbana viabiliza linhas de fuga para outras possíveis realidades. Distante de um andamento cotidiano, coloca a vida em questão; deste modo, os afazeres dos que ali transitam se diluem à medida que o interesse pela eventualidade cresce.

Este movimento que se cria em meio à multidão nos impele à reflexão sobre a ideia de biopoder que foi cunhada por Michel Foucault em meados de 1970. Por este seguimento da com- 
preensão dos sistemas relacionais e da estruturação social, o corpo se encontra com seus potenciais subjetivos subjugados ao controle e modelação. Agora, tudo que escapa ao biopoder tem vida curta em sua atividade, entretanto esta brevidade é geralmente acompanhada de grande potência de libertação da subjetividade no que tange à criatividade do sujeito perante a vida, tanto dos que proporcionam o momento como dos que ali comungam da situação.

Com esta reflexão, adentramos neste modo de resistência por meio da arte, que não almeja mais um ideal de revolução ou substituição do poder vigente, mas tem intenção de existir em concomitância ao poder estabelecido na rede social, esta que autorregulamenta a vida, impedindo seu exercício de livre expressão, em que o sujeito é coagido muitas vezes pelos próprios pares de determinado grupo social. Assim, derivamos esta argumentação sobre as duas obras que se encontram na fricção entre sistemas ou em zonas liminares.

É por meio deste caráter de resistência apontado - que também pode ser definido como uma re-existência - , que compatibilizamos a vida do fazer cotidiano despotencializada pela estruturação do biopoder com uma vida potente apresentada pelos artistas. A definição desta resistência é bem colocada por Oliveira em seu livro "Corpos Indisciplinados: Ação cultural em tempos de biopolítica", ao pontuar que:

A resistência atual, ao não mais lutar pelo poder e não se guiar pela noção de finalidade enfatizando o processo como elemento fundamental, inscreve-se na esfera mais ampla da cultura [...] na medida em que a ênfase não é mais no fim a ser alcançado e sim no processo como agente transformador (OLIVEIRA, 2007, p. 17).

Resistir, para o fazer artístico aqui tratado, é criar mecanismos de desestruturação simbólica da dinâmica urbana; é, por assim dizer, permitir que algo se modifique na percepção dos transeuntes que ali circulam. Em Filoctetes, o tempo-espaço se dilata em favor de debate público que é gerado no entorno dos bonecos, já em Mugre esse deslocamento é feito com a reapropriação de um corpo que ali se encontrava em estado de abandono social. Ao transitar com o mendigo em seus ombros, Sandoval cria uma poética da resistência ao evidenciar o descaso; ao entrar na galeria de arte rompe também com padrões históricos de utilização do espaço, bem como da caracterização de um artista e do material usado para criação (mendigo).

Aos desavisados, as duas ações podem se parecer como uma leve provocação, no entanto na simplicidade de ambas está o segredo da potência da ação que se revela não na técnica do artista, mas na situação que ela cria para a percepção dos pre- 
sentes. Há nas duas abordagens um deslocamento e fragmentação de qualquer linguagem artística: elas não se ajustam em definições pois estão demasiadamente ocupadas com o incômodo sentido pelo artista, este que é o motivador da criação.

Encerramos este artigo entendendo que um dos principais mecanismos para as ações que fazem um diálogo direto com o "real da vida" se caracteriza como uma ruptura de linguagem e a hibridação da abordagem que escapa de definições pela tangente que se reporta ao engajamento político social da obra.

Em síntese, este artigo procurou associar as ideias tangentes entre arte e sociedade, mais especificamente as relações imbricadas nas performances de cunho social e político realizadas na América Latina. Para tanto, a escolha das duas obras performáticas Mugre e Filoctetes vieram como suporte para discutir conceitos chave que têm permeado as práticas no universo da performance na contemporaneidade, tais como "liminaridade" e "chaveamento". A convergência temática, bem como o modo de relacionar a obra com o espectador, seja por meio do Mugre (mendigo) ou bonecos de látex, traz uma reflexão social/política acerca dos sujeitos situados nas "margens", trazendo uma nova maneira de olhar e experienciar essa presença em situação liminar. Tendo em vista tais reflexões apresentadas ao longo do artigo, é possível afirmar que a fronteira entre arte e vida nas práticas contemporâneas tem sido cada vez mais "borrada", hibridada, possibilitando novos meios de convívio com a arte. 
CARLSON, Marvin. Performance: uma introdução crítica. Belo Horizonte: editora UFMG, 2009.

DAWSEY, John C. Turner, Benjamin e antropologia da performance: o lugar olhado (e ouvido) das coisas. CAMPOS-Revista de Antropologia Social, v. 7, n. 2, 2006.

DEWEY, John. Arte como experiência. São Paulo, Martins Fontes. 2010.

GASTALDO, Édison. Goffman e as relações de poder na vida cotidiana. Revista Brasileira de Ciências Sociais. Vol. 23. N.68, outubro/2008.

OLIVEIRA, Lúcia Maciel Barbosa de. Corpos indisciplinados. Ação cultural em tempos de biopolítica. Ed. Beca São Paulo, 2007.

SARTIN, Philippe Delfino. Sobre liminaridade: relendo Victor Turner em chave pós-estrutural. Revista de Teoria da História, v. 6, n. 2, 2011.

TURNER, Victor. O Processo Ritual. Petrópolis: Vozes, 1974. 